\title{
Correction to: Mobile device use among preschool-aged children in Greece
}

\author{
Stamatios Papadakis ${ }^{1}$ (D) Foteini Alexandraki ${ }^{1} \cdot$ Nikolaos Zaranis $^{1}$
}

Published online: 6 October 2021

(c) Springer Science+Business Media, LLC, part of Springer Nature 2021

\section{Correction to: Education and Information Technologies https://doi.org/10.1007/s10639-021-10718-6}

The presentation of the author names in the original version of this article was incorrect. The correct author names are now presented in this erratum.

The authors apologize for the oversight and for any confusion it may have caused.

The original article has been corrected.

Publisher's note Springer Nature remains neutral with regard to jurisdictional claims in published maps and institutional affiliations.

The original article can be found online at https://doi.org/10.1007/s10639-021-10718-6.

Stamatios Papadakis

stpapadakis@uoc.gr

1 Department of Preschool Education, School of Education, University of Crete, Rethymnon, Greece 